\title{
An experimental investigation on stall flutter over a vertically mounted rigid finite wing
}

\author{
R. F. Soares ${ }^{1 *}$, I.Karasu ${ }^{2}$, B. Ganapathisubramani ${ }^{1}$ \\ ${ }^{1}$ University of Southampton, Southampton, SO17 1BJ, United Kingdom \\ ${ }^{2}$ Adana Alparslan Turkes Science and Technology University, 01250, Saricam, Turkey \\ *R.F.Soares@soton.ac.uk
}

\begin{abstract}
As stall flutter has relevant engineering implications, such as in blades of wind turbine and HALE (highaltitude long-endurance aircraft). This work presents the experimental investigation of rigid wing setup in a closed-circuit wind tunnel having $2.1 \mathrm{~m} \times 1.5 \mathrm{~m}$ test section. The experimental campaign reached stable and symmetrical LCO within the freestream range from $9 \mathrm{~m} / \mathrm{s}$ up to $14 \mathrm{~m} / \mathrm{s}\left(1.69 \times 10^{5}<\operatorname{Re}<2.63 \times 10^{5}\right)$. Two techniques were used for position tracking: one mechatronic and one image-based. The latter used 'shakethe-box' method applied to a body, which has proven a successful approach as a non-intrusive tool.
\end{abstract}

\section{Introduction}

The experiments were carried out at the 7x5 Wind Tunnel; a closed-circuit facility with two test sections in serial. For this experiment, the setup was installed at the high-speed test section $(2.1 \mathrm{~m} \times 1.5 \mathrm{~m})$. The wing is a NACA0012 cross-section model of aluminium (.e. structure) and carbon-fibre composite (e.g. skin) of $0.3 \mathrm{~m}$ chordwise and a span length of $0.77 \mathrm{~m}$. A servo motor with cylindrical shield is the base for the wing, which was connected to a 6-axis Delta IP65 load cell.

In the heaving axis, the system was attached to a pair of linear-guided carriages, and the nominal rest position is found after two identical, counterbalance springs were linked, providing a spring constant $(\mathrm{k})$ of 400 $\mathrm{N} / \mathrm{m}$. In the pitching axis, one pair of identical rubber bands were used on each side, connecting the wing leading edge to the cylindrical base. The image-based tracking solution involved Particle Tracking Velocimetry (PTV) with 'shake-thebox' methodology, where 5 Phantom V641 high-speed cameras recorded a scattered pattern of $8 \mathrm{~mm}$ dots on the wing surface. Experimental setup is illustrated in Figure 1.

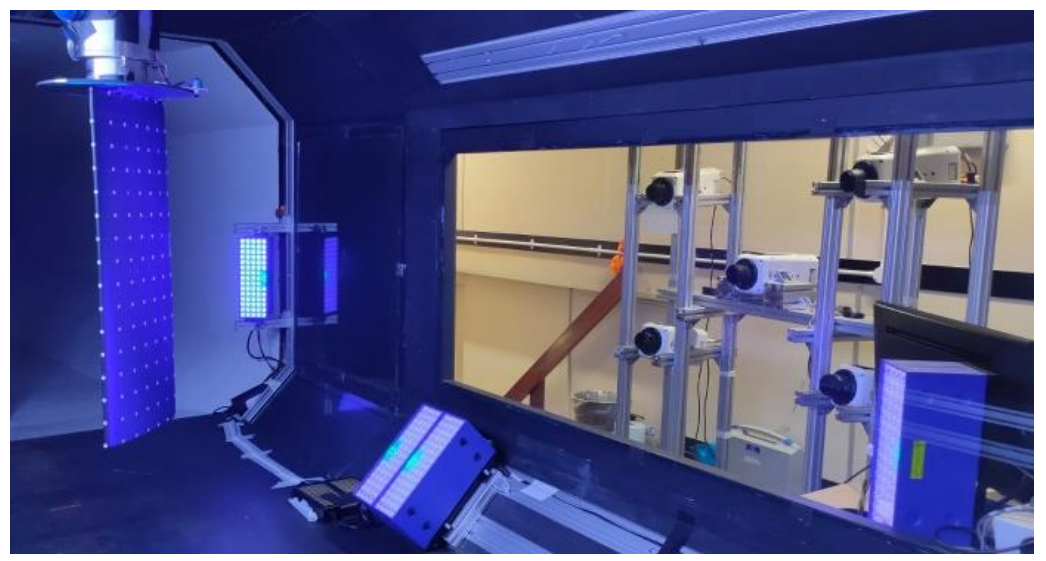

Figure 1: Wing system and 'shake-the-box' hardware setup for structural analysis. 


\section{Summary of Results}

Both position tracking tools were performed simultaneously and lately compared in order to assess the quality of the image-based technique as a surface tracking tool. The later were processed in two steps: (i) obtaining the time-resolved position tracking with 'shake-the-box' methodology, then (ii) reconstruction of the wing surface and estimation of the angular and heaving history. Assuming the mechatronic position tracking results as baseline, the non-intrusive results are compared and presented in Figure 2.

A nominally harmonic dataset were found for each self-sustained LCO, which allowed analysis in phaseaveraged format (Figure 3), where the properties are averaged as a function of the angle of attack cycle (i.e. pitching motion) discretised within $1^{\circ}$ resolution.
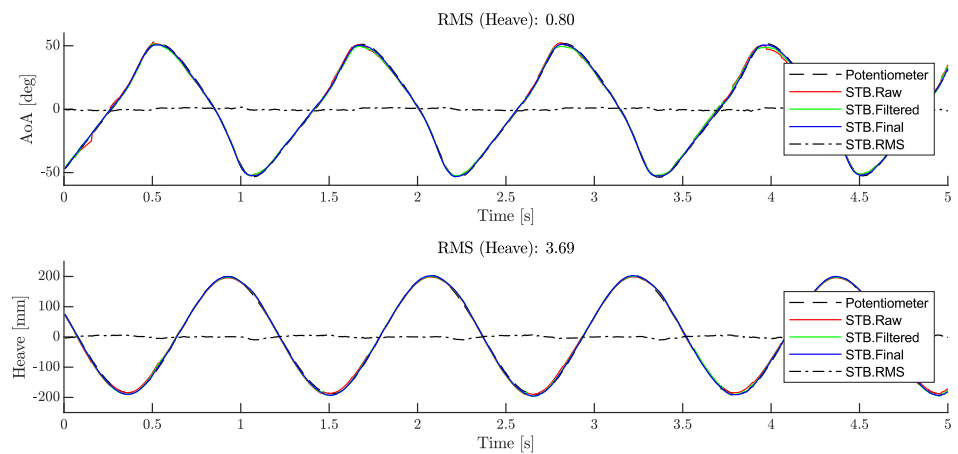

Figure 2: Position tracking validation:

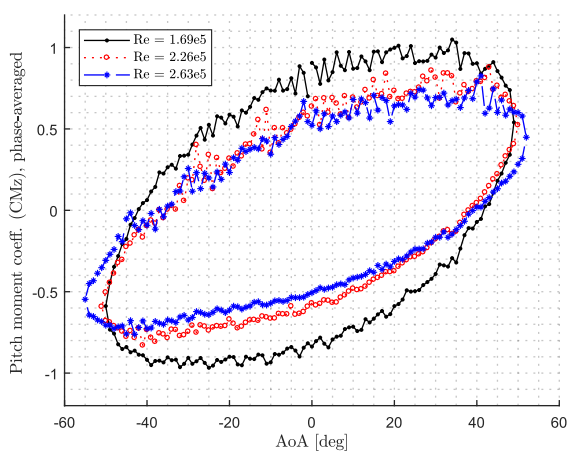

mechatronic- vs image-based systems.

Figure 3: Phase-averaged LCO's.

\section{Conclusions}

The occurrence of a self-sustained LCO were found of the system with a NACA0012 rigid wing. An initial perturbation was required to trigger the phenomenon; however, the motion amplitudes were noticeably stable and reproducible for a same trigger input.The absolute minimum freestream able to sustain the motion was $8.5 \mathrm{~m} / \mathrm{s}$ with minor decay instabilities, and any freestream higher than $14 \mathrm{~m} / \mathrm{s}$ would reach the physical end-stops. The 'Shake-the-Box' method applied as a body tracking solution has been successfully validated, allowing the use of this approach as a non-intrusive tool for further applications.

\section{Acknowledgements}

We gratefully acknowledge the financial support from EU H2020 project HOMER (Grant Ref No: 769237).

\section{References}

[1] G. Dimitriadis and J. Li, "Bifurcation Behavior of Airfoil Undergoing Stall Flutter Oscillations in LowSpeed Wind Tunnel," AIAA Journal, vol. 47, no. 11, pp. 2577-2596, Nov. 2009.

[2] D. Poirel and F. Mendes, "Experimental Small-Amplitude Self-Sustained Pitch-Heave Oscillations at Transitional Reynolds Numbers," AIAA Journal, vol. 52, no. 8, pp. 1581-1590, Aug. 2014. 